\title{
Construction Logistics Improvements Using the SCOR Model - Tornet Case
}

\author{
Fredrik Persson, Jonas Bengtsson, and Örjan Gustad \\ Department of Science and Technology \\ Linköping University, Campus Norrköping \\ S-601 74 Norrköping, Sweden \\ fredrik.persson@liu.se
}

\begin{abstract}
The cost for house production is rising in Sweden. Compared with other consumer goods, the cost for houses have had a steeper increase over the last decades. Initiatives such as Lean Construction and Prefabrication have emerged in the construction industry to reduce the cost of house production and thereby the cost of the house itself. These initiatives have collected a lot of ideas and tools from the automotive industry and a lot of good examples are emerging that leads to cost reductions in construction. In this strive towards improvement, logistics activities are emerging as important processes and a potential for cost savings. This paper reports on a project at the construction company Peab where the SCOR-model (Supply Chain Operations Reference Model) have been utilized in order to find processes with high cost saving potential. The result reports on cost savings from the logistics perspective in different areas of the logistic system.
\end{abstract}

Keywords: Construction Industry, Construction Logistics, Supply Chain Management, SCOR.

\section{Introduction}

During the last decade, construction logistics have become more and more in focus both from academia but also from practitioners. It is believed that much can be gained by implementing the ideas and theories from the very broad logistics filed. All that is needed is a little tweaking to make the theories suitable for the construction industry. Although there is an increasing interest for research in construction logistics, one can notice a clear trend in publications. That is the division of, on the one hand logistics from raw materials to the construction site, rather a supply chain management initiative, and on the other hand, the construction site logistics, more internal logistics on the actual site. This research originates in the idea that these two logistics initiatives cannot and should not be divided, but that the uniqueness of construction logistics is the incorporation of site logistics into the whole supply chain management theory. With this in mind, this study of supply chains in the construction industry is a step forward, both for the definition of construction logistics, but also for the supply chains in the construction industry. 
The logistics systems in the construction industry take up a large part of the total costs and affect the total lead time in any construction project. Large amounts of money can be saved if supply chain operations can be made in a more standardised way, learning from previous projects or using standard solutions. Today, however, it seems that every new building project is reinventing the management of supply chains.

The construction industry is in some countries considered as the backbone of their economy. This large sector with a highly traditional business approach is closely interlinked with the rest of the economy [1]. In Sweden (during 2007), more than 73.000 companies compete in the industry with a total turnover of approximately EUR 37 billions and 225.000 employees [2]. The construction industry is basically a project based industry. Every construction site is considered a project and many projects are performed simultaneously. The productivity development in the construction industry is slow compared to other industries [3]. Much of the blame for the slow productivity gain is the high cost levels throughout the industry. According to Vrijhoef and Koskela [3] the high costs are to be blamed on the supply chain and its involvement of many subcontractors and both local and global suppliers.

Vrijhoef and Koskela [3] propose four roles of supply chain management in the construction industry covering the supply logistic part of the chain. To some extent their model has provided useful information regarding coordination between supply chain and construction site but the model is limited to supply chains and does not cover supply networks. Vidalakis and Tookey [4] use simulation to study a supply chain in the construction industry. They draw on the similarities between a manufacturing supply chain and a construction supply chain. Differences are functional and located at the end of the supply chains; otherwise they find no major parts where the two supply chains differ.

The purpose of this paper is to analyse a construction site with a supply chain management view utilising common supply chain analysis tools, in this case the SCOR model [5]. For the case company, the purpose is to evaluate the use of the SCOR model and to find areas of improvement that can reduce costs or in any other way increase profitability or reduce the environmental impact of a construction project.

The paper is structured as follows. Chapter 2 presents the case company Peab and the building project Tornet. Chapter 3 is a theoretical outlook into the area of construction logistics. Chapter 4 is the case study. Chapter 5 ends the paper with some conclusions and acknowledgements.

\section{The Case Company Peab}

Peab AB (Peab) is one of the largest companies on the Swedish construction market. The company has about 11,000 employees and an annual turnover of about EUR 3.6 billions, for 2008 [6].

The building called Tornet (the Tower) is the final stages of construction work during the summer of 2009. The building is located in Tornby city in Linköping, Sweden. Peab started to build Tornet in September 2007 and it is planned to be finished in 
summer of 2009. The 19 storey high building will rise 64 meters off the ground, which for Linköping is quite high, only shadowed by the Cathedral. . Tornet will accommodate offices, business apartments and conference facilities.

Material that arrives at construction sites requires human resources for unloading; mostly there is also need for handling equipment as an aid in this process. This handling equipment often needs to be rented. When delays occur the equipment cannot be used, they will generate unnecessary costs. At the construction site The Tower this has been solved with a nearby handling equipment rental service. Peab has the opportunity to rent the handling equipment when needed. A bad delivery performance results in interruptions of the work, the personnel need to unload the material instead of finishing their planned tasks. Personnel who wait for delayed deliveries lead to an increased waste of time of the human resources, time that could be used for value adding tasks. Another problem that can occur is that nobody is able to receive the delivery.

The products which will be included in this study are plasterboards, doors and kitchens. The reasons why these particular products have been chosen are the following: plasterboards are chosen because of the common use of this product in the construction industry. Doors and kitchens are also chosen based on their commonality. Also, they have been subjected to delivery disturbances and quality problems for the examined construction site.

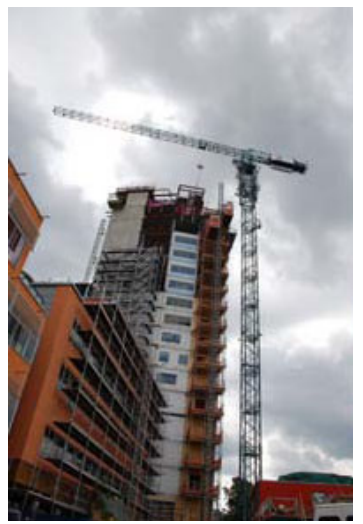

Fig. 1. Tornet (The Tower) during construction

\section{The Supply Chain in the Construction Industry}

The supply chain in the construction industry varies from the traditional supply chain in the manufacturing industry, where raw material is delivered to a production site for further transformation to a finished product and later distributed to the costumers. The construction industry is characterized by the production site being built up around the building that is about to be manufactured. The construction industry is also characterized by temporary supply chains with fragmentation and instability as a result. Even 
though some processes in the construction industry seem to be similar, there tends to be no standard in them [3]. According to Vrijhoef and Koskela [3] the construction industry is an example of make-to-order, MTO. Other authors consider the construction industry to be a typical example of engineer-to-order, ETO [7].

The supply chain in the construction industry is in need of change according to Xue et al. [8]. There are, however, barriers and problems that prevent coordination and integration of the supply chain. Examples of problems are attitude-related problems, myopic focus, lack of understanding for suppliers and subcontractors. Furthermore the lack of communication in the construction industry contributes to inferior transparency in the supply chain. Tight schedules and unrealistic lead-time requirements for material and equipment lead to further problems [8]. Many of the problems are caused in earlier stages in the supply chain than where they discovered [3].

During the work with the case, it became obvious that construction logistics needed a unique definition since several issues made it difficult to solely rely on common definitions of logistics for other industries. It became also very clear that logistics is a too narrow term for the purpose at hand. Although the work still focuses on logistics improvements, a glance at supply chain management was needed. Stadtler [9] defines SCM such as: "The task of integrating organizational units along a supply chain and coordinating materials, information and financial flows in order to fulfill the (ultimate) customer demands". Construction SCM can be defined, following Stadtler's [9] definition, as: The task of integrating organizational units along a supply chain, including the construction site and subcontractors, and coordinating materials, information and financial flows with the project site plan in order to fulfill the (ultimate) customer demands".

\section{SCOR Mapping of the Supply Chain}

A mapping of the material flow of plasterboards, doors and kitchens have been performed with SCOR in levels 2 and 3. First, the material flow for these particular items, from supplier to the construction site, has been analysed in the SCOR methodology in level 2, see Figure 2. The mapping was used to visualize and identify possible problems within the material flow. To identify further problems in the supply chain processes at the construction site, secondly, a mapping at SCOR level 3 has been made for each of the three product types, see Figure 3 for plasterboards. The mapping for plasterboards is presented in detail in this paper in the following subchapters.

\subsection{Plasterboards}

When Peab has been assigned a building project, the process to develop a production schedule (D3.3) begins, see also Figure 3. The production schedule is based on backward planning by using a Gantt chart. As the project continues, work on developing construction plans (M3.1) takes place. The plan enables scheduling of production activities (M.3.2). 


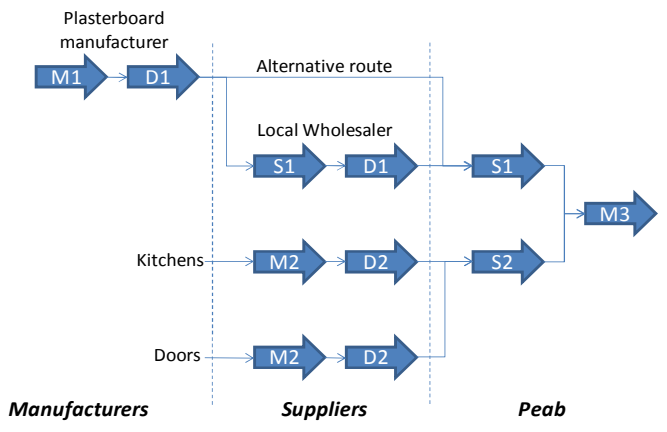

Fig. 2. SCOR mapping in level 2

The schedule of production activities (M3.2) is used as a support for the call off process (S1.1). Another process that supports the call offs is the delivery plan (P2.4). Call offs for plasterboards are made by mail to the local retailer. The retailer delivers orders that are below five tonnes in weight, bigger orders will be shipped directly from the manufacturer. When the plasterboards arrive, the product is considered received (S1.2). The reception of plasterboards takes place at a nearby yard because of the lack of space. As the products are received, verification (S1.3) is performed. After the verification the products are transferred to the construction site with rented machines. At the construction site, the plasterboards are distributed to the right floor for assembly (S1.4). The invoice is then compared to the delivered quantity (S1.5). When needs arise on a floor due to miscalculations, plasterboards are, if possible, transferred from floors above (M3.3). Assembled boards are inspected by craftsmen (M3.4). Waste is thrown in a container for landfill (M3.8).

At Tornet construction site most of the deliveries were not time bound. With current costs, for rental of machines and time bound deliveries, the rent for machines exceeds the cost for time bound deliveries when delays exceed one hour.

Perfect order fulfilment. The data was hard to collect because of the lack of access to documentation. Some of the gathered data did not include all the desired metrics. This applied to all the investigated products. Data was gathered from delivery notes that were compared to the call offs and order acknowledgements; additional complementary data were obtained from the manager at the construction site. The results for the plasterboards are as follows:

- $\%$ of ordered Delivery in Full. All orders contained the right products, 95 percent of them also arrived in the right quantity.

- Delivery Performance to Customer Commit Date. All orders were shipped to the right geographical location, but only 50 percent were delivered on time. All the orders that arrived on time were also delivered in full, according to the first level 2 metric.

- Documentation Accuracy. The investigation for this metric only included plans for assembly. This was, however, not relevant for plasterboards.

- Perfect Condition. There was no information of damaged plasterboards; however this is not a likely scenario and indicates a lack of documentation. 


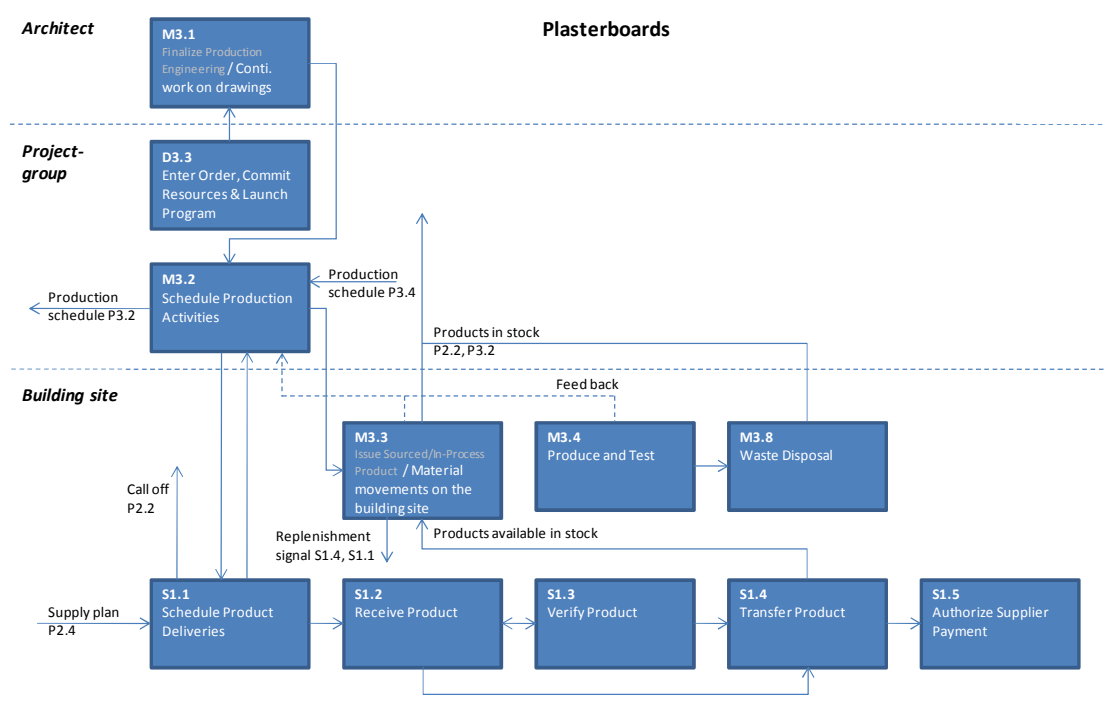

Fig. 3. SCOR mapping of plasterboards at Tornet

Because of the lack of documentation when it comes to damaged products, the results for perfect order fulfilment tend to be higher than the actual value for plasterboards. The results for doors and kitchens will not be explained in detail but the result is presented in Table 1 .

Supplier plasterboards. Figure 2, that illustrates the material flow to the Tornet construction site, indicates that Peab is using unnecessary intermediaries. This extra step in the supply chain generates unnecessary costs. Even though larger orders are shipped directly from the supplier, the call off is made to the retailer who wants his share. The majority of the call offs are performed by mail, even though Peab has a purchase and procurement system. If Peab used the purchase and procurement system (EDI) when ordering gypsum boards, they would acquire an EDI-discount. With the EDI and quantity discounts, which they receive when using direct deliveries, Peab obtains a total discount of 24 percent compared to the retailers' price. Even though only ten percent of the plasterboard deliveries are ordered from the retailer, there is still a potential saving, see Table 2 .

Table 1. Perfect order fulfilment

\begin{tabular}{lccc}
\hline & $\begin{array}{c}\text { Plasterboards } \\
{[\%]}\end{array}$ & $\begin{array}{c}\text { Doors } \\
{[\%]}\end{array}$ & $\begin{array}{c}\text { Kitchens } \\
{[\%]}\end{array}$ \\
\hline Orders Delivered in Full & 95 & 57 & 0 \\
Delivery Performance to & 50 & 57 & 33 \\
Customer Commit Date & - & 100 & 100 \\
Documentation Accuracy & 100 & 86 & 100 \\
Perfect Condition & $\mathbf{5 0}$ & $\mathbf{5 7}$ & $\mathbf{0}$ \\
\hline Perfect Order Fulfilment & & & \\
\hline
\end{tabular}


Table 2. Savings when using the EDI system and direct deliveries (Costs in SEK)

\begin{tabular}{llll}
\hline & EDI System & Direct deliveries & Total savings \\
\hline Tornet & 16000 & 22000 & $38000(\sim 4 \%)$ \\
Total 2007* & 106000 & 147000 & $253000(\sim 4 \%)$ \\
\hline
\end{tabular}

* For region Linköping, 2007.

Handling of plasterboard waste. Peab's supplier of plasterboards receives and recycles plaster waste as well as damaged boards. This service is provided without fees as long as the moisture level for the plaster is less than seven percent. For higher moisture levels a small fee is charged for each tonne. Currently all plaster waste is sent to landfill. Although the cost for landfill is almost 1000 SEK per tonne of waste it is currently cheaper than recycling because of the significant transportation costs.

\subsection{Other Suppliers and Products}

The deliveries of doors have often been incomplete and are subjected to delays. The incomplete orders have generated more deliveries and increased costs due to increased administration. Another problem with the incomplete orders is that it has been impossible to follow the production plan. When Peab fails to follow the production plan, they are forced to keep the received doors in stock. Stocks lead to increased time spent on searching for the desired product as well as decreased space and increased risk for damages to the products.

The deliveries of kitchens have also been subjected to delays and incomplete orders. The most frequent problem concerns the kitchen doors or rather the lack of them. Not a single delivery that was examined contained the ordered kitchen doors. In addition the supplier of kitchens has not informed Peab when delays have occurred. To get the information about the deliveries, the construction site manager was forced to contact the supplier by himself. These circumstances make it impossible to follow the production plan and Peab is forced to do a time consuming rescheduling, since the installation of the kitchens cannot be completed.

Perfect order fulfilment for these two products, doors and kitchens, are presented in Table 1.

\subsection{Consolidation Point, Terminal}

Highly frequent products, such as plasterboards, wood products and isolation, which are often standardized, can with advantage be kept in stock at a consolidation point, in this case in a terminal. Using the purchasing and procurement system the call offs in the region should be consolidated. This would give Peab economy of scale towards their suppliers. The terminal enables the possibility to consolidate different products at the construction site, which leads to increased filling ratio in the trucks and fewer deliveries to the construction sites. Another advantage is the closeness of the terminal with the possibility of increased delivery precision. Not all the products need to be kept in stock since the point also enables cross docking.

The establishment of a terminal is a step towards centralization. Centralization would decrease the total amount of products kept in stock. Fewer products at the 
construction site leads to increased space and decreased search time for desired products. The terminal also becomes a natural consolidation point for the plasterboard waste. When the waste is gathered, Peab will get economy of scale in the transports to the manufacturer. The cost for recycling will then be lower than the current costs for landfill. The greatest benefit from the recycling is, though, the environmental aspect.

\section{Conclusions}

This case study in the construction industry pinpoints some of the problems construction logistics (or rather construction SCM) are facing in order to help the business as a whole to be more productive and to reach lower costs in the future. The SCOR model proved a useful tool in this case study. However, the use of SCOR was not straight forward. It is obvious that the SCOR model is not developed and maintained with the construction industry in mind. The authors would like to thank Brains and Bricks $\left(\mathrm{B}^{2}\right)$ who made this research possible (www.liu.se/b2/).

\section{References}

1. Olsson, F.: Supply Chain Management in the Construction Industry - Opportunity or Utopia?, Licentiate Thesis, Lund University, Department of Design Sciences, Logistics (2000)

2. SCB: www.scb.se (accessed July 8, 2009)

3. Vrijhoef, R., Koskela, L.: The four roles of supply chain management I construction. European Journal of Purchasing \& Supply Management 6 (2000)

4. Vidalakis, C., Tookey, J.E.: Conceptual functions of a simulation model for construction logistics. In: Joint International Conference on Computing and Decision Making in Civil and Building Engineering, pp. 906-915 (2006)

5. SCC (2009), http: / / www . supply-chain. org (accessed July 8, 2009)

6. Peab AB (2009), http: / / www . peab. se (accessed July 8, 2009)

7. Persson, F., Engevall, S.: The shift from construction site to prefabrication in the construction industry: A case study. In: APMS 2008 (2008)

8. Xue, X., Wang, Y., Shen, Q., Yu, X.: Coordination mechanisms for construction supply chain management in the Internet environment. International Journal of project management 25 (2007)

9. Stadtler, H.: Supply Chain Management - An Overview. In: Stadtler, H., Kilger, C. (eds.) Supply Chain Management and Advanced Planning, pp. 7-28. Springer, Berlin (2000) 